\title{
Design, fabrication and testing of sandwich panel decking for use in road freight trailers
}

(Journal of Sandwich Structures and Materials)

\section{Authors:}

Joel Galos ${ }^{a,}{ }^{*}$, Michael Sutcliffe ${ }^{a}$, Golam Newaz ${ }^{b}$

a Department of Engineering, University of Cambridge, Trumpington Street, Cambridge CB2 1PZ, UK

${ }^{\mathrm{b}}$ Department of Engineering, Wayne State University, 5050 Anthony Wayne Drive, Detroit, MI 48202, USA

* Corresponding Author. Tel: +44 (0)1223-332996. Email address: jlg62@cam.ac.uk (J.L. Galos)

\begin{abstract}
This paper investigates the potential of sandwich structures in the novel application of road freight trailer decking. Sandwich panels are developed to be lightweight replacements to conventional birch plywood hardwood decking, which is the norm in European road freight trailers. A tailored material selection process is used to identify the most advantageous sandwich panel material combinations with respect to flexural properties and material cost. Sandwich panels with woven glass fibre reinforced polyester and an end-grain balsa are found to be the most advantageous material combination in terms of both raw material cost and mechanical performance. These panels are fabricated using a single shot fabrication technique and are approximately $30 \%$ lighter than conventional birch plywood trailer decking. This weight saving corresponds to approximately $165 \mathrm{~kg}$ in a standard $13.6 \mathrm{~m}$ long European road freight trailer. Three point bend testing has shown that these sandwich panels have superior flexural strength and comparable flexural stiffness to birch plywood. Large panel testing confirmed that these panels can withstand roughly four times the forklift wheel load likely to be seen in-service. The shear properties of two grades of rigid end-grain balsa core are also studied to illustrate the importance of using a higher density balsa core. Practical considerations, such as joining and recyclability, for using sandwich panels in this application are also discussed.
\end{abstract}

\section{Keywords:}

Sandwich design, applications, decking, road freight, balsa core, flexural testing. 


\section{Introduction}

In road haulage the empty weight of a vehicle is a significant contributor to fuel consumption and resulting $\mathrm{CO}_{2}$ emissions. Therefore, by reducing the empty mass of the trailer, the energy efficiency of the vehicle as a whole can be improved [1]. Figure 1 shows the weight percentage contributions of major structural components in a $13.6 \mathrm{~m}$ long flatbed road freight trailer, commonly found in Europe and the United Kingdom (UK). It is evident that trailer decking, which is typically hardwood-based, contributes a significant proportion of weight and is therefore a good choice of sub-component to target for lightweighting. Using a lightweight deck in trailer design is also significantly easier to implement practically compared to altering the design of steel chassis beams or the running gear.

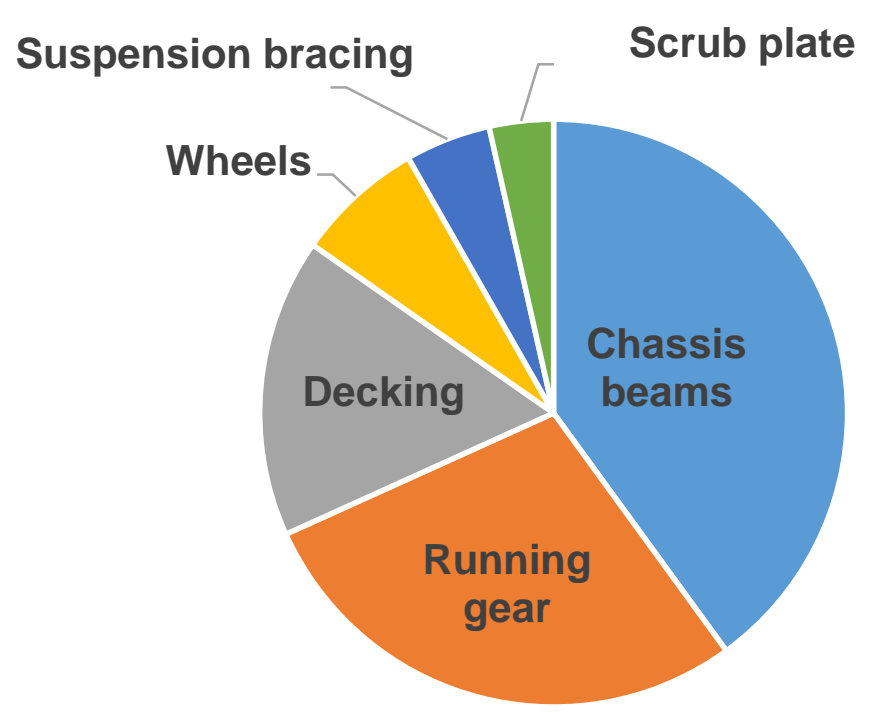

Figure 1. Typical weight breakdown of a standard $13.6 \mathrm{~m}$ long flatbed dry freight trailer (not including trailer walls and body).

There are numerous kinds of deck material currently used in trailers; the foundation of the majority of these is hardwood, either in a monolithic or layered ply form. The exposed surface of the deck is typically covered in a non-slip, water-resistant material. For example; half lapped keruing (hardwood) decking is often used in conjunction with an aluminium tread overlay. Another typical example is birch plywood which is made from birch plies bonded with phenolic adhesive and then covered with phenolic resin that is hot pressed to give a non-slip surface. The geometry and mass characteristics of common existing deck materials are described in Table 1. These decks are typically designed in accordance with ISO 1496: The specification and testing of general cargo containers for general purposes [2]. 
Table 1. Characteristics of existing hardwood based road freight deck materials typically used throughout Europe and the UK. Total mass calculation assumes a deck area of $27 \mathrm{~m}^{2}$.

\begin{tabular}{cccc}
\hline & $\begin{array}{c}\text { Nominal } \\
\text { thickness } \\
(\mathrm{mm})\end{array}$ & $\begin{array}{c}\text { Areal } \\
\text { mass } \\
\left(\mathrm{kg} / \mathrm{m}^{2}\right)\end{array}$ & $\begin{array}{c}\text { Total } \\
\text { mass } \\
(\mathrm{kg})\end{array}$ \\
\hline Euck material (Trade name) & 28 & 18.2 & 491 \\
Birch plywood (WISA-Trans) & 30 & 21.0 & 567 \\
\hline
\end{tabular}

The structural configuration of a lightweight trailer deck could take many potential forms, including: monolithic panels, stiffened panels, sandwich panels and hybrid panels (e.g. fibre reinforced foam-core sandwich panels). However, the highly cost-driven nature of trailer construction, as well as the geometry of the conventional steel trailer chassis, makes sandwich panels a strong candidate for use in this application. The use of a sandwich could help increase flexural strength and rigidity, whilst simultaneously reducing weight [3]. Indeed, the structure of conventional road freight semi-trailers is strikingly similar to pedestrian bridges, where sandwich panel decks have been applied over steel beams with good success. The success of sandwich panels in replacing plywood panels in the side walls of box-type road freight trailers is also encouraging for their application to trailer decking.

Some work has been done to lightweight laminated oak wood trailer decks, which have been the mainstay trailer deck material in North America for over four decades. For example, Havco Products LLC produce laminated oak decks that are backed with glass fibre reinforced epoxy to increase panel stiffness, while decreasing weight [4]. The composite stiffened oak panel is reported to be about $90 \%$ stronger than a monolithic oak panel and this extra strength allows for a reduction in thickness. The product has been tested in trailers for more than ten years and has been commercially produced since 2000 . Some research has also been conducted on lightweighting oak trailer decking through the application of a sandwich panel composed of ribbed fibre-reinforced plastic face sheets and a core of extruded aluminium tubes [5]. Both glass fibre reinforced epoxy face sheets and carbon fibre reinforced epoxy face sheets were considered. The panels were reported to be significantly stiffer than monolithic oak decking and brought a weight saving of up to $68 \%$.

The aim of this paper is to illustrate the potential of sandwich panels for use in road freight trailer decking as a means of significantly reducing trailer weight without compromising mechanical performance or chassis beam design. Through a close examination of the design 
constraints specific to this application, a tailored material selection methodology is developed which ensures that a balance between material cost and mechanical performance can be met. The methodologies for sandwich optimisation developed by Steeves and Fleck [6] are also applied here. Test specimens and larger demonstrator panels are built and tested in three point bending to illustrate proof of concept.

\section{Design constraints}

It is desirable that sandwich panel decking is designed so that it can be fitted or retrofitted to existing trailer chassis designs, so that existing chassis beams do not need to be modified. Matching the dimensions of the replacement deck with the hardwood based materials will help achieve this. Conventional hardwood decks are typically inserted between the transverse beams and the top flange of the main longitudinal beams of the chassis, though they may also be laid directly over the longitudinal beams. Hence, the nominal thickness of the deck should be approximately 28 - $30 \mathrm{~mm}$ (Figure 2) and it should have comparable flexural properties to hardwood based decking, particularly at a span length of approximately $450 \mathrm{~mm}$, which is the maximum typical spacing between transverse members in a standard $13.6 \mathrm{~m}$ trailer (Figure 3).

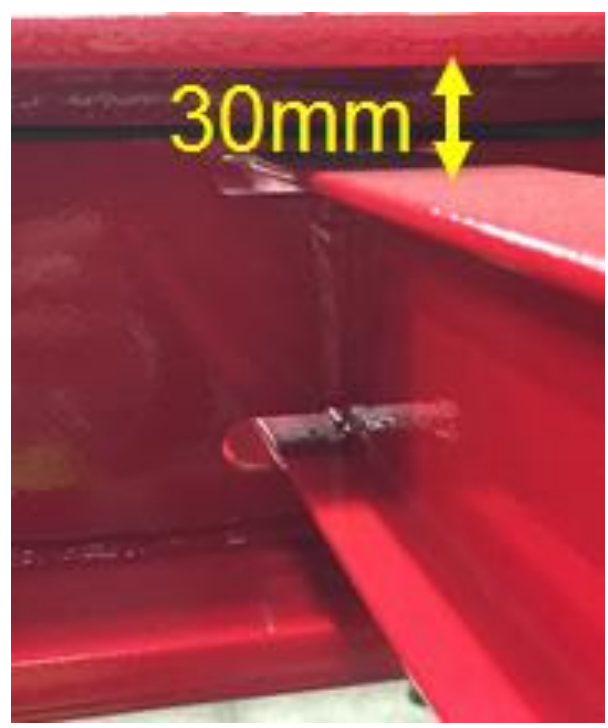

Figure 2. Spacing between the transverse and longitudinal beam members in a $13.6 \mathrm{~m}$ flatbed chassis determines the required sandwich panel thickness. Image courtesy of SDC Trailers Ltd. 


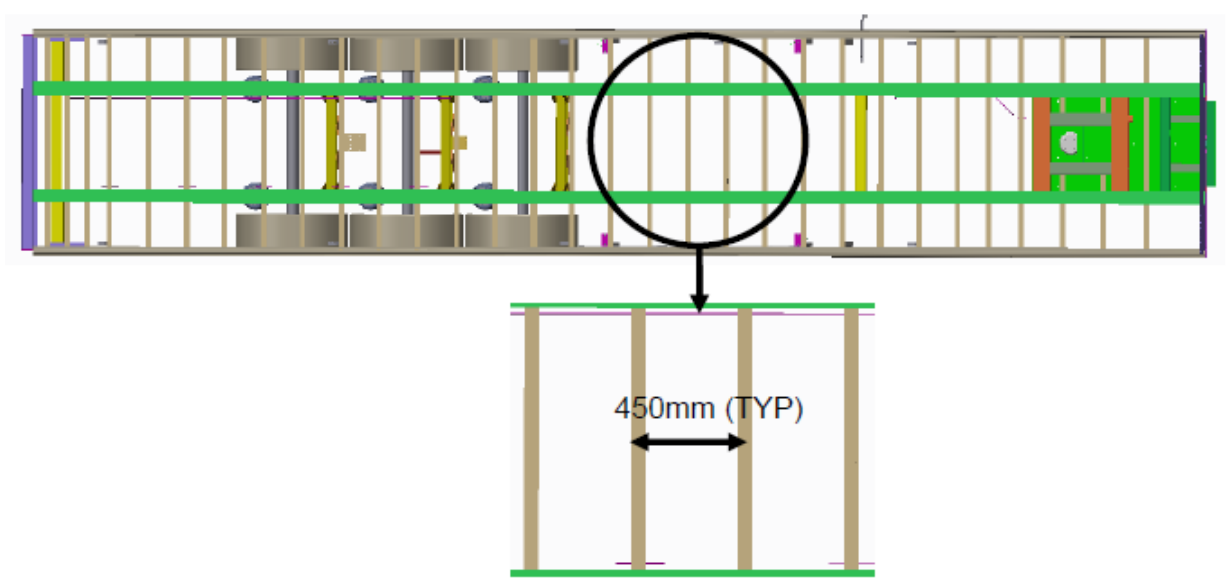

Figure 3. Plan view of the typical (TYP) spacing between the transverse members in a $13.6 \mathrm{~m}$ flatbed chassis, which determines the required span length $L$ subjected to three point bending. Image courtesy of SDC Trailers Ltd.

In addition to loading and geometry requirements, the extremely cost-driven nature of the construction of road freight trailers dictates that above all, sandwich panel trailer decking must be cost competitive against conventional hardwood based decking. Discussions with industrial partners indicate that the industry is willing to undertake a trial of new decking systems should the relative material cost be less than two times that of existing hardwood decking and the weight saving be significant (around 30\%).

\section{Material selection and detailed design}

Material selection indices

The first step in sandwich panel design is to develop a material selection process for the face sheets and core. To help achieve this, material selection software CES EduPack 2013 [7] is used to identify potential material combinations that will allow the sandwich panel to match or exceed the performance of hardwood in three point bending and at the same time be lighter. Many different material combinations typically used in sandwich panel construction are considered, along with other common monolithic materials for comparison. A list of the different material combinations considered for use in the sandwich panel is provided in Table 2. All possible combinations of face sheet and core materials were considered. The resulting material selection plot (Figure 4) is created based on a beam in three point bending. The plot identifies the materials that match or exceed the performance of birch hardwood in three point bending, by maximising stiffness $M_{1}$ (Equation 1) and strength $M_{2}$ (Equation 2) selection indices as defined by Ashby [8]. 


$$
\begin{aligned}
& M_{1}=\frac{E_{b}{ }^{1 / 2}}{\rho} \\
& M_{2}=\frac{\sigma_{b}^{2 / 3}}{\rho}
\end{aligned}
$$

Table 2. Face sheet and structural core materials considered in the sandwich panel material selection process.

\begin{tabular}{cc}
\hline Potential face sheet materials & Potential core materials \\
\hline Woven E-glass fibre / polyester (GFRP) & End-grain balsa wood \\
E-glass fibre / epoxy laminate & Nomex honeycomb \\
Carbon fibre / epoxy laminate & Polypropylene (PP) honeycomb \\
Aluminium & PP foam \\
Hardwood & Aluminium honeycomb \\
& Aluminium foam \\
& Polycarbonate (PC) foam \\
& Polyvinylchloride (PVC) foam \\
& Phenolic foam \\
\end{tabular}

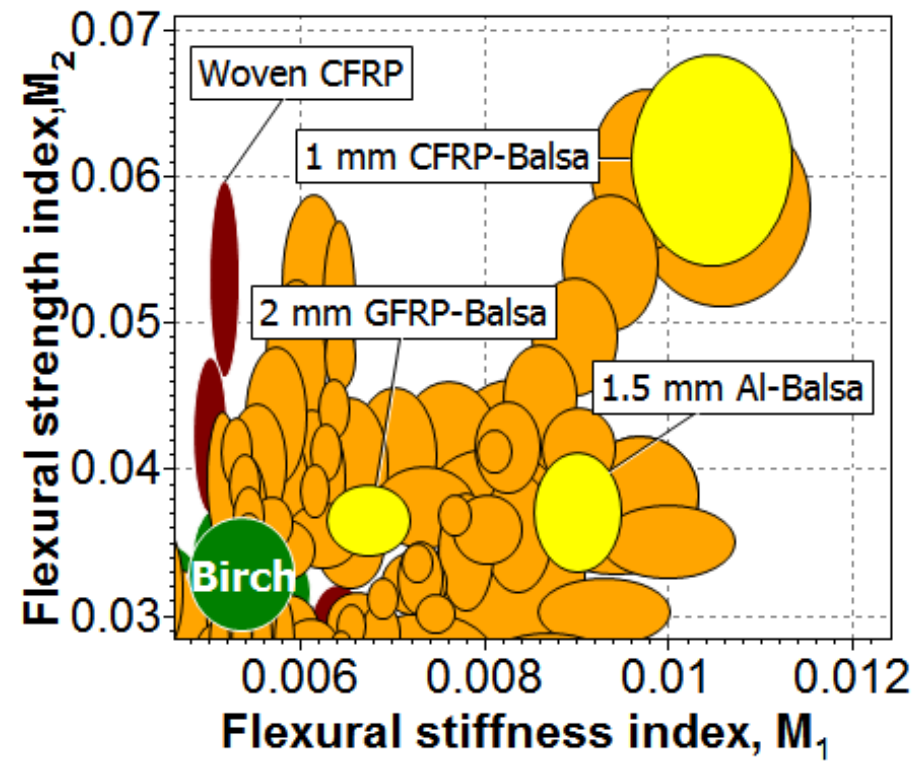

Figure 4. Material selection plot for a beam in three point bending developed in CES Edupack 2013 [7]. Orange and yellow markers indicate sandwich panels that match or exceed the performance of birch hardwood (shown in green) in three point bending. 
During the material selection process it was assumed that the sandwich panel face sheet thickness varied from $1 \mathrm{~mm}$ (with a $26 \mathrm{~mm}$ core) to $4 \mathrm{~mm}$ (with a $20 \mathrm{~mm}$ core). This was done to ensure that the sandwich panel has a nominal thickness of $28 \mathrm{~mm}$ to match the thickness of typical birch plywood decking. A nominal thickness of $28 \mathrm{~mm}$ will also allow enough room for a non-slip surface coating to be applied.

\section{Detailed design}

Because material selection here is largely driven by cost, many of the sandwich panel material combinations that are common in other industries, such as aerospace, are far less feasible for use here, despite their superior mechanical properties. The materials identified as being acceptable from the material selection plot (Figure 4) are analysed in terms of their relative cost and relative mass, and the cheapest successful material combinations are shown in Table 3. The sandwich panel material combinations not shown in Table 3 are considered to be unsuitable for use here since they do not meet the weight and mechanical performance requirements. The exact minimum face sheet thicknesses $t_{\min }$ required to match the stiffness and strength of birch plywood are found by considering the minimum collapse load and flexural rigidity of each of the sandwich panels, using average material properties provided in CES Edupack 2013 [7]. The minimum collapse load is determined by considering competing collapse modes (Appendix A). The results of this procedure are summarised in Table 3.

Table 3. Minimum face sheet thickness and failure modes for various sandwich panels $(28 \mathrm{~mm}$ total thickness) with either woven GFRP or aluminium face sheets. Symbols correspond to those shown in

Figure 5. Specific gravity of structural cores shown in brackets.

\begin{tabular}{llccc} 
& \multicolumn{1}{c}{ Material combination } & $\begin{array}{c}t_{\text {min }} \\
(\mathrm{mm})\end{array}$ & $\begin{array}{c}\text { Design } \\
\text { driver }\end{array}$ & Collapse mode \\
\hline 0 & GFRP - end-grain (0.2) balsa & 2.4 & Stiffness & Core shear \\
$\Delta$ & GFRP - PP (0.6) foam & 2.3 & Stiffness & Elastic indentation \\
$\square \quad$ GFRP - PVC (0.3) foam & 2.3 & Stiffness & Elastic indentation \\
$\nabla$ & GFRP - PU (0.3) foam & 2.5 & Strength & Elastic indentation \\
- & Aluminium - end-grain (0.2) balsa & 1.2 & Strength & Face yield \\
$\Delta$ & Aluminium - PP (0.6) foam & 1.2 & Strength & Face yield
\end{tabular}


- Aluminium - PVC (0.3) foam

$\boldsymbol{\nabla}$ Aluminium - PU (0.3) foam
1.2 Strength

1.7 Strength
Face yield

Elastic indentation

It can be seen in Figure 5 that sandwich panels comprised of an end-grain balsa core with either woven GFRP or aluminium face sheets are the most advantageous in terms of raw material cost and mass. Hence, these are selected for further investigation. These panels can significantly reduce mass, while keeping the increase in raw material cost within the upper bound that has been estimated from discussions with industrial partners.

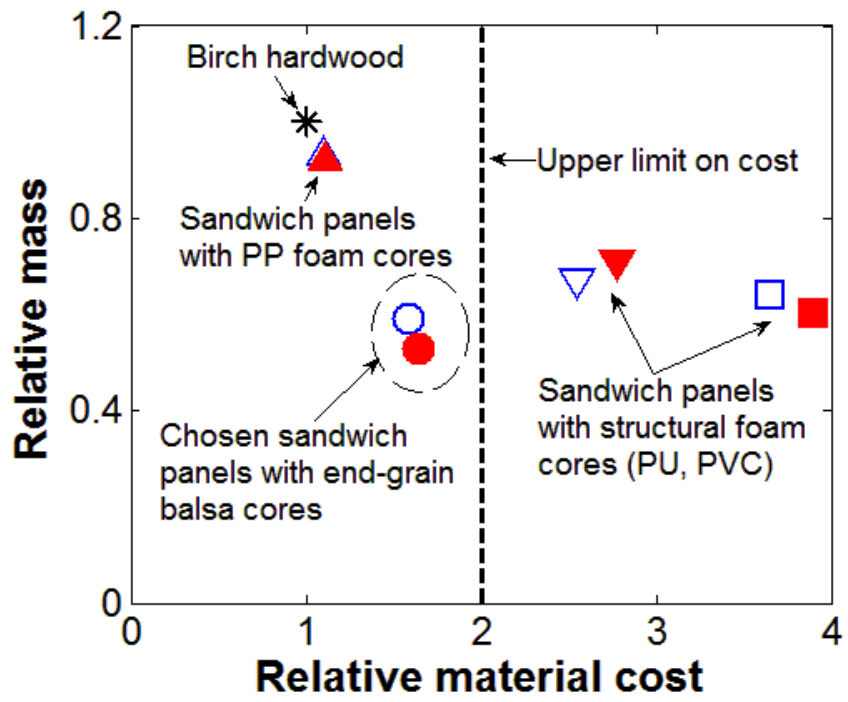

Figure 5. Plot of relative mass against relative cost for the eight cheapest acceptable sandwich material combinations identified from the three point bending material selection plot. Unfilled markers: sandwich panels with woven GFRP face sheets. Solid markers: sandwich panels with aluminium face sheets. Key see Table 3.

\section{Choice of raw materials}

Bi-axial plain weave E-glass fibre fabric (areal weight $290 \mathrm{~g} / \mathrm{m}^{2}$ ) and high quality general purpose (orthophthalic) polyester laminating resin, were selected for use in the GFRP face sheets owing to their low cost. Methyl ethyl ketone peroxide (MEKP) catalyst is used as the catalyst for the polyester resin. The raw materials used in these face sheets were supplied by Easycomposites Ltd, UK.

A $1.5 \mathrm{~mm}$ thick aluminium $(5052 \mathrm{H} 32)$ tread plate is chosen for use in the top face sheet of the aluminium sandwich panels and a $1.2 \mathrm{~mm}$ thick high strength aluminium (6082 T6) sheet is used in the bottom face sheet. The selected tread plate is the thinnest available. These face sheets were supplied by Switchblade Metals Ltd, UK. The benefits of using aluminium tread 
plate as the top face sheet of sandwich panels in mass transport applications have been well documented [9].

Rigid end-grain balsa core sheets (Figure 6), comprised of many constituent blocks of balsa bonded together with polyvinyl acetate (PVA) adhesive, were used in all sandwich panels and were supplied by Gaugler \& Lutz oHG, Germany. Material properties of the chosen face sheet materials and end-grain balsa core are shown in Tables 4 and 5 respectively. Table 5 shows the relevant material properties of three commercially available end-grain balsa cores taken from the manufacturer data sheet [10]. Both the intermediate density core (tradename Baltek SB.100) and the higher density core (tradename Baltek SB.150) are selected for investigation.

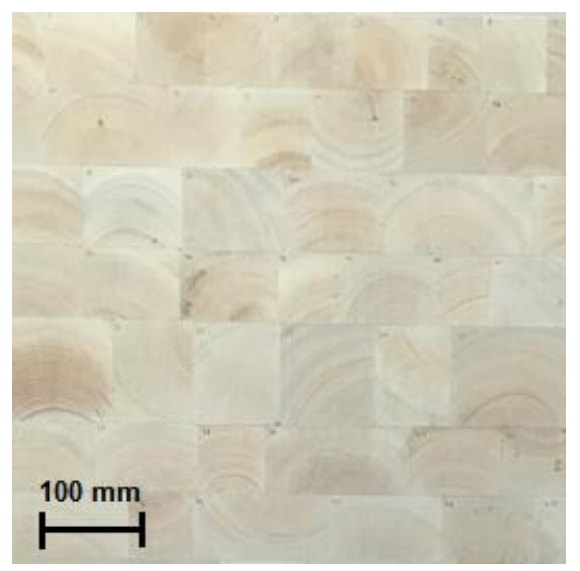

Figure 6. Baltek SB.100 rigid end-grain balsa core sheet comprised of many constituent blocks bonded together with PVA adhesive.

Table 4. Material properties of selected face sheet materials. Flexural properties determined through flexural testing with span length $=120 \mathrm{~mm}$, loading/support roller diameter $=19 \mathrm{~mm}$, specimen length $=160 \mathrm{~mm}$, specimen width $=25 \mathrm{~mm}$ and test speed $=5 \mathrm{~mm} / \mathrm{min}$. (Minimum of five specimens tested in every case and average values reported). Flexural stiffness determined from the initial slope in the load-displacement curve.

\begin{tabular}{ccccc}
\hline & $\begin{array}{c}\text { Nominal } \\
\text { thickness } \\
(\mathrm{mm})\end{array}$ & $\begin{array}{c}\text { Measured } \\
\text { density } \\
\left(\mathrm{kg} / \mathrm{m}^{3}\right)\end{array}$ & $\begin{array}{c}\text { Ultimate } \\
\text { flexural } \\
\text { strength } \\
(\mathrm{MPa})\end{array}$ & $\begin{array}{c}\text { Flexural } \\
\text { stiffness } \\
(\mathrm{GPa})\end{array}$ \\
\hline Seven ply bi-axial weave GFRP & 2.1 & 1,900 & 370 & 22 \\
Aluminium tread plate (5052 H32) & 1.5 & 2,700 & 360 & 65 \\
Aluminium sheet (6082 T6) & 1.2 & 2,700 & 490 & 77 \\
\hline
\end{tabular}


Table 5. Material properties of end-grain balsa core [10].

\begin{tabular}{cccccc}
\hline Tradename & $\begin{array}{c}\text { Nominal } \\
\text { density } \\
\left(\mathrm{kg} / \mathrm{m}^{3}\right)\end{array}$ & $\begin{array}{c}\text { Shear } \\
\text { strength } \\
(\mathrm{MPa})\end{array}$ & $\begin{array}{c}\text { Shear } \\
\text { modulus } \\
(\mathrm{MPa})\end{array}$ & $\begin{array}{c}\text { Compressive } \\
\text { strength } \\
(\mathrm{MPa})\end{array}$ & $\begin{array}{c}\text { Compressive } \\
\text { modulus } \\
(\mathrm{MPa})\end{array}$ \\
\hline Baltek SB.50 & 109 & 1.8 & 136 & 22 & 1,616 \\
Baltek SB.100 & 148 & 2.6 & 187 & 65 & 2,526 \\
Baltek SB.150 & 285 & 5.2 & 362 & 77 & 4,428 \\
\hline
\end{tabular}

\section{Failure mode maps}

Failure mode maps (Figures 7 and 8) are constructed following the methods outlined by Gibson and Ashby [11] using the material properties in Tables 4 and 5. Minimum mass trajectories are plotted onto the maps using the procedure outlined by Steeves and Fleck [6] (details in Appendix B). Note that the current designs are slightly thicker than the original proposed thickness of $28 \mathrm{~mm}$, owing to the closest suitable thicknesses of off-the-shelf raw materials. The total thickness of both panels is $30 \mathrm{~mm}$, which is still acceptable for this application.

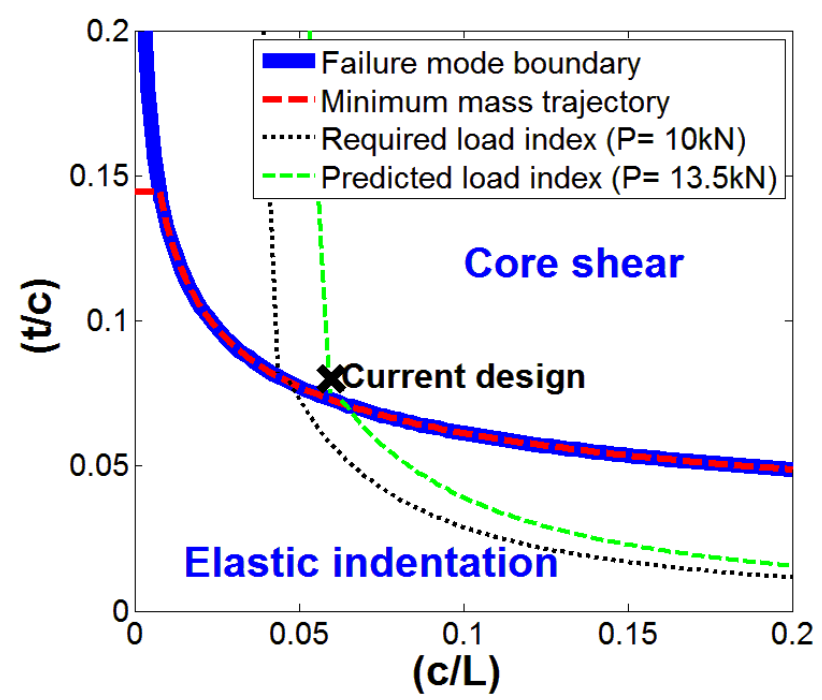

Figure 7. Failure mode map for sandwich panels with a woven GFRP face sheets of thickness $t$, an end-grain balsa core of thickness $c$ and an unsupported span length $L$. Current design: $2.1 \mathrm{~mm}$ thick face sheets and $25.4 \mathrm{~mm}$ thick core. 


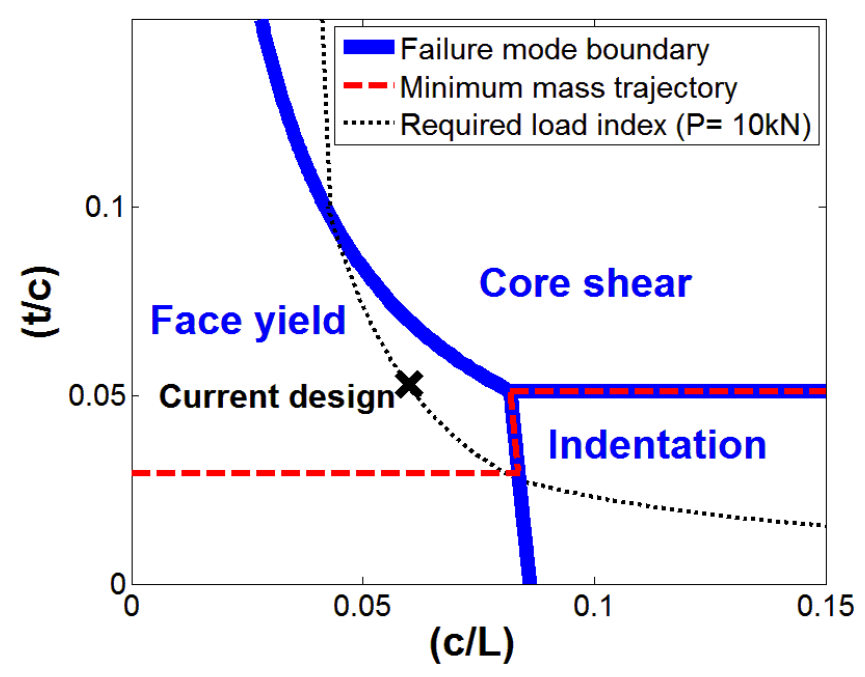

Figure 8. Failure mode map for sandwich panels with aluminium face sheets of thickness $t$, an endgrain balsa core of thickness $c$ and an unsupported span length $L$. Current design: $1.5 \mathrm{~mm}$ thick top face sheet (tread plate), $1.2 \mathrm{~mm}$ bottom face sheet and $25.4 \mathrm{~mm}$ thick core.

\section{Panel fabrication}

There are several potential strategies that could be used to fabricate the two selected sandwich panels, particularly with respect to the woven GFRP sandwich panel. This panel can be manufactured with a single shot process where the face sheets are cured and bonded to the balsa core simultaneously, or they could be manufactured by a multi-stage process by which the face sheets are cured then bonded to the core, or indeed a combination of these strategies known as a co-bonding process could be used. Both the multi-stage process and the single shot process are chosen for further investigation as they are the most likely to be implemented practically. However, should these sandwich panels be mass produced for commercial use, a single shot manufacturing process would most likely be more desirable as it removes the need for costly structural adhesives, helping to keep material costs to a minimum.

Woven GFRP panels are fabricated using a wet hand lay-up process and left to cure under heat lamps. It was found that seven layers of $290 \mathrm{~g} / \mathrm{m}^{2}$ woven glass fibre fabric produced a desirable average thickness of $2.1 \mathrm{~mm}$. Care was taken during the wet hand lay-up process to thoroughly roll the polyester resin into the dry fabric to minimise the number of voids, though the inherent lack of pressure in the process results in voids being present in the final laminate (Figure 9 (b)). Whilst a vacuum infusion process would likely significantly reduce the void volume fraction, the increased costs associated with this process make it less desirable for use here. The panels made with the single shot process are shown in Figure 9. 


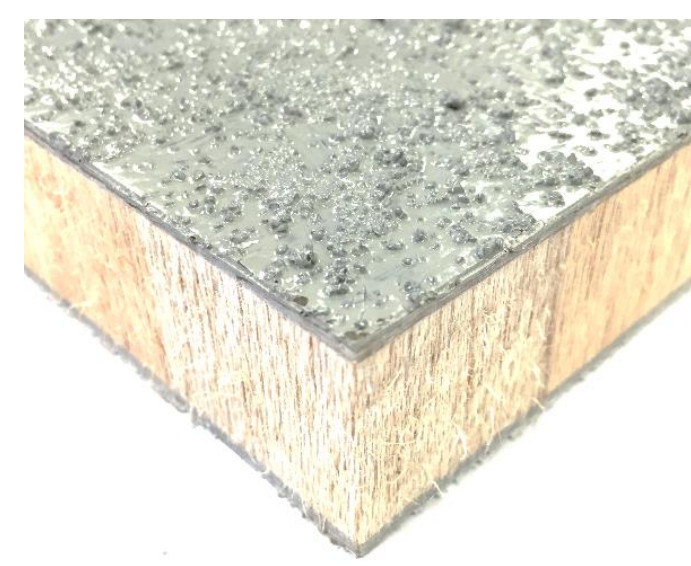

(a)

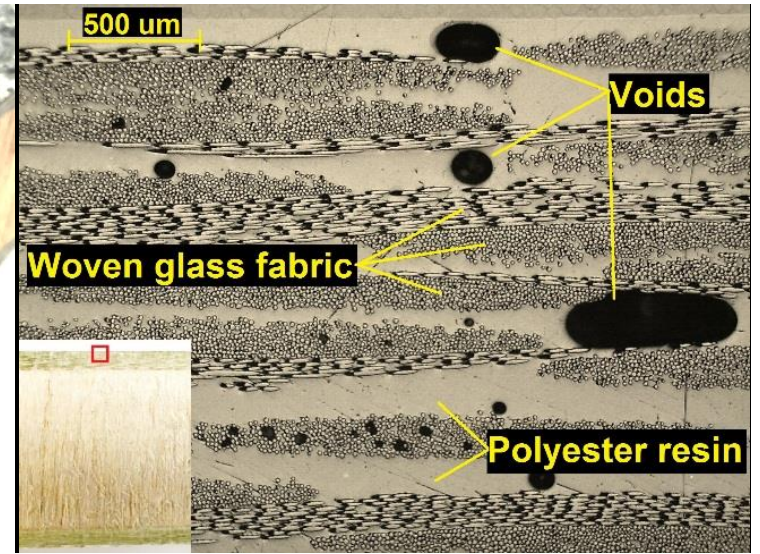

(b)

Figure 9. (a) Woven GFRP-balsa (SB.150) sandwich panel manufactured with a single shot process

(2.1 $\mathrm{mm}$ thick face sheets and $25.4 \mathrm{~mm}$ thick core) and with a non-slip polyamine epoxy coating applied. (b) Micrograph of GFRP face sheet used in sandwich panel construction, showing the presence of numerous voids introduced during the wet hand lay-up of the face sheets (typical cross section inset).

During the single shot fabrication process, the end-grain balsa core is laid directly over the bottom face sheet before the resin cures and the top face sheet is subsequently laid up over the core. In the multi-stage fabrication process, on the other hand, cured GFRP panels are bonded to the end-grain balsa core using methacrylate adhesive (VuduGlu VM100), which typically has good bond strength with GFRP (Figure 10 (a)). The surface of the GFRP to be bonded is cleaned with distilled water to help improve the adhesion of the face sheet to the core.

Due to long lead times associated with acquiring $25.4 \mathrm{~mm}$ thick rigid SB.100 end-grain balsa core, two pieces of $12.7 \mathrm{~mm}$ thick core are used in replacement of the $25.4 \mathrm{~mm}$ thick core. The two $12.7 \mathrm{~mm}$ thick cores are bonded together with a structural epoxy adhesive (Permabond ET515). The superior mechanical properties of the adhesive compared to the core helps to ensure that this has minimal impact on overall panel performance. Panels that were constructed with the denser SB.150 core all used a $25.4 \mathrm{~mm}$ thick rigid core that did not require this additional fabrication step.

The sandwich panels with aluminium face sheets (Figure 10 (b)) are fabricated by bonding the face sheets to the core using either methacrylate adhesive (VuduGlu VM100) or structural epoxy adhesive (Permabond ET515). Prior to bonding, the surface of the aluminium to be bonded is roughened with grit paper then degreased with acetone to help improve adhesion of the face sheet to the core. The weight characteristics of all SB.150 sandwich panels are 
compared to birch plywood in Table 6 , and it can be seen that the single shot GFRP panel provides the greatest weight saving benefit.

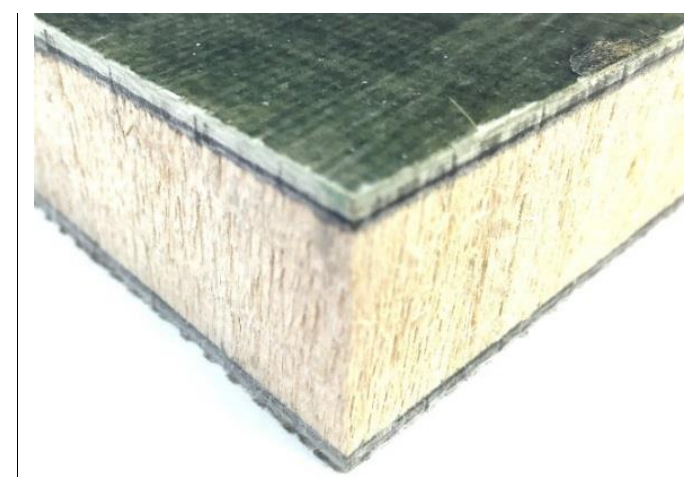

(a)

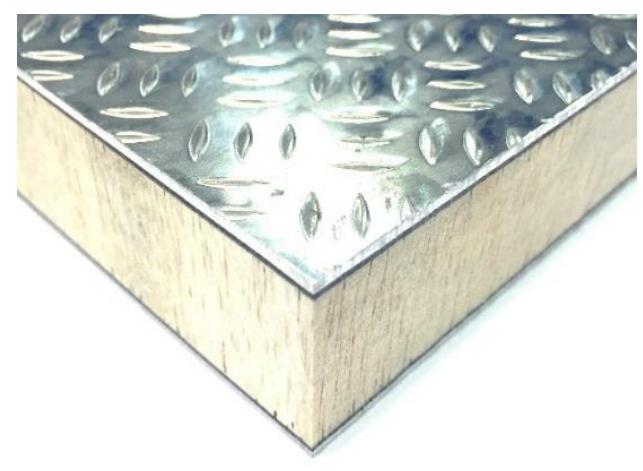

(b)

Figure 10. (a) Woven GFRP-balsa (SB.150) sandwich panel $(2.1 \mathrm{~mm}$ thick face sheets and $25.4 \mathrm{~mm}$ thick core). (b) Aluminium-balsa (SB.150) sandwich panel (1.5 mm thick $5052 \mathrm{H} 32$ tread plate top face sheet, $1.2 \mathrm{~mm}$ thick $6082 \mathrm{~T} 6$ bottom face sheet and $25.4 \mathrm{~mm}$ thick SB.150 core). Panels are constructed by bonding the face sheets to the core with methacrylate adhesive.

Table 6. Comparison of the weight characteristics of sandwich panels with higher density (SB.150) end-grain balsa cores to birch plywood decking. Total mass calculation assumes a deck area of $27 \mathrm{~m}^{2}$.

\begin{tabular}{lccccc}
\hline Deck type & $\begin{array}{c}\text { Density } \\
\left(\mathrm{kg} / \mathrm{m}^{3}\right)\end{array}$ & $\begin{array}{c}\text { Nominal } \\
\text { thickness } \\
(\mathrm{mm})\end{array}$ & $\begin{array}{c}\text { Areal } \\
\text { mass } \\
\left(\mathrm{kg} / \mathrm{m}^{2}\right)\end{array}$ & $\begin{array}{c}\text { Total } \\
\text { mass } \\
(\mathrm{kg})\end{array}$ & $\begin{array}{c}\text { Weight } \\
\text { saving } \\
(\%)\end{array}$ \\
\hline Birch plywood & 700 & 30 & 21.0 & 567 & 0 \\
GFRP-balsa SB.150 (single shot) & 498 & 30 & 14.9 & 403 & 29 \\
GFRP-balsa SB.150 (methacrylate) & 515 & 31 & 16.0 & 431 & 24 \\
Al-balsa SB.150 (methacrylate) & 529 & 30 & 15.9 & 428 & 24 \\
\hline
\end{tabular}

\section{Mechanical testing}

Three point bending tests are performed to determine the flexural stiffness and strength of the fabricated sandwich panels, as well as conventional birch plywood. The test set up and specimen parameters are shown in Figure 11. A span to thickness ratio of approximately 15/1 is used to help ensure that the specimens will fail in bending. The span length of $428 \mathrm{~mm}$ used in testing was the maximum allowable span length given the fixture and test machine used. This is close to the $450 \mathrm{~mm}$ span length that is typically used in a standard $13.6 \mathrm{~m}$ UK road freight trailer. All three point bend tests are performed on an Instron 5500R Universal Test 
Machine using a test speed of $5 \mathrm{~mm} / \mathrm{min}$. A laser displacement sensor is used to capture displacement at the mid-span of the bottom face sheet.

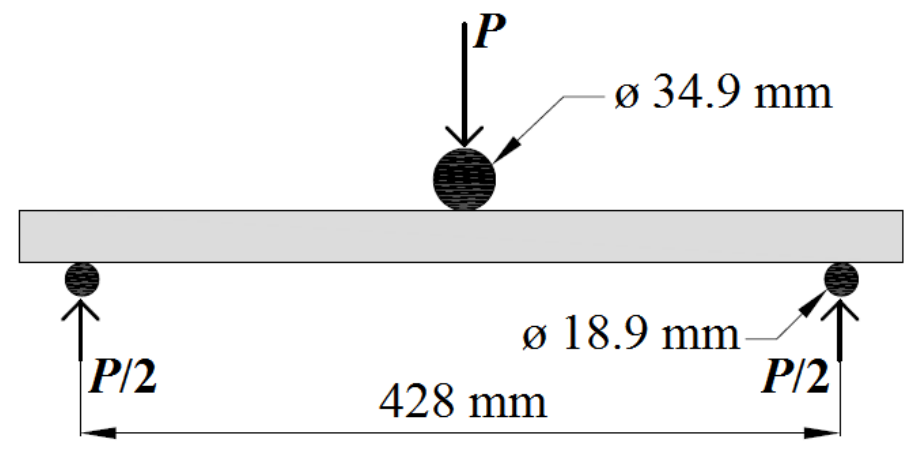

FRONT VIEW

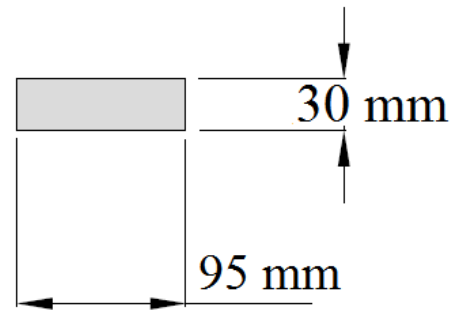

SIDE VIEW

Figure 11. Nominal specimen dimensions and test parameters used in flexural testing, with an applied load $P$. Test speed $=5 \mathrm{~mm} / \mathrm{min}$.

Panel testing on larger demonstrator panels is also performed to simulate loading from a forklift wheel that is commonly seen in-service. Large panels with dimensions of 550 × $400 \times 30 \mathrm{~mm}$ were simply supported between two rollers (diameter $76 \mathrm{~mm}$ ), providing an unsupported span length of $500 \mathrm{~mm}$ as shown in Figure 12. The panels were loaded through a rubber pad in the centre of the mid-span over a contact area of $180 \times 80 \mathrm{~mm}$. The contact patch area of the rubber pad simulates a forklift wheel and is chosen as per the recommendations in ISO 1496: The specification and testing of general cargo containers for general purposes [2]. A laser displacement sensor is also used in this test to determine the displacement at the centre underside of the panel.

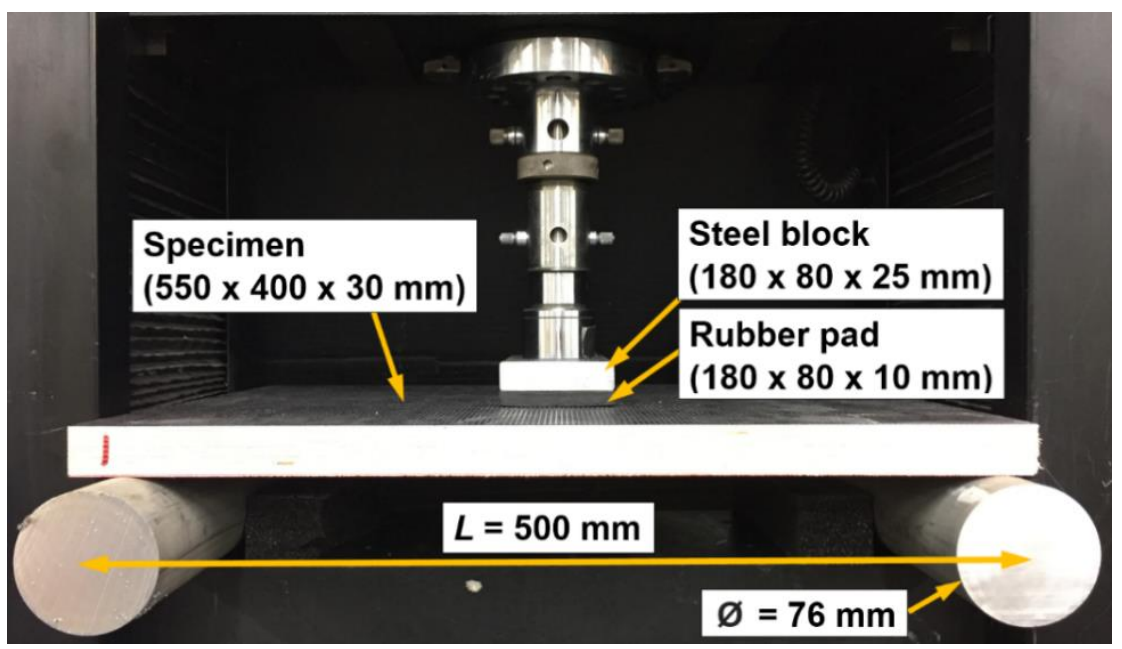

Figure 12. Panel testing setup with simulated forklift wheel contact. Test speed $=5 \mathrm{~mm} / \mathrm{min}$. 


\section{Results and discussion}

Typical load-displacement curves for the sandwich panels with SB.150 end-grain balsa cores tested in three point bending are shown in Figure 13, along with load-displacement curves of conventional birch plywood decking of the same nominal dimensions. Figure 14 plots the mean ultimate load and mean flexural modulus for all of the sandwich panel specimens tested. The flexural modulus is calculated from the gradient of the initial linear portion of the loaddisplacement curve obtained during testing. It is evident from Figures 13 and 14 that the sandwich panels with high density (SB.150) cores generally have superior flexural strength and comparable flexural stiffness in comparison to birch plywood. The majority of the sandwich panel specimens with SB.100 grade cores failed prematurely in core shear and did not exhibit the desired flexural properties. The sandwich panel specimens with GFRP face sheets typically failed in core shear (Figure 15 (a)), while the methacrylate bonded aluminium sandwich panels typically failed through face sheet yielding, followed by core shear failure (Figure 15 (b)), as predicted by the failure mode maps (Figures 7 and 8). On the other hand, the aluminium sandwich panel specimens bonded with epoxy adhesive exhibited premature debonding of the face sheets from the core.

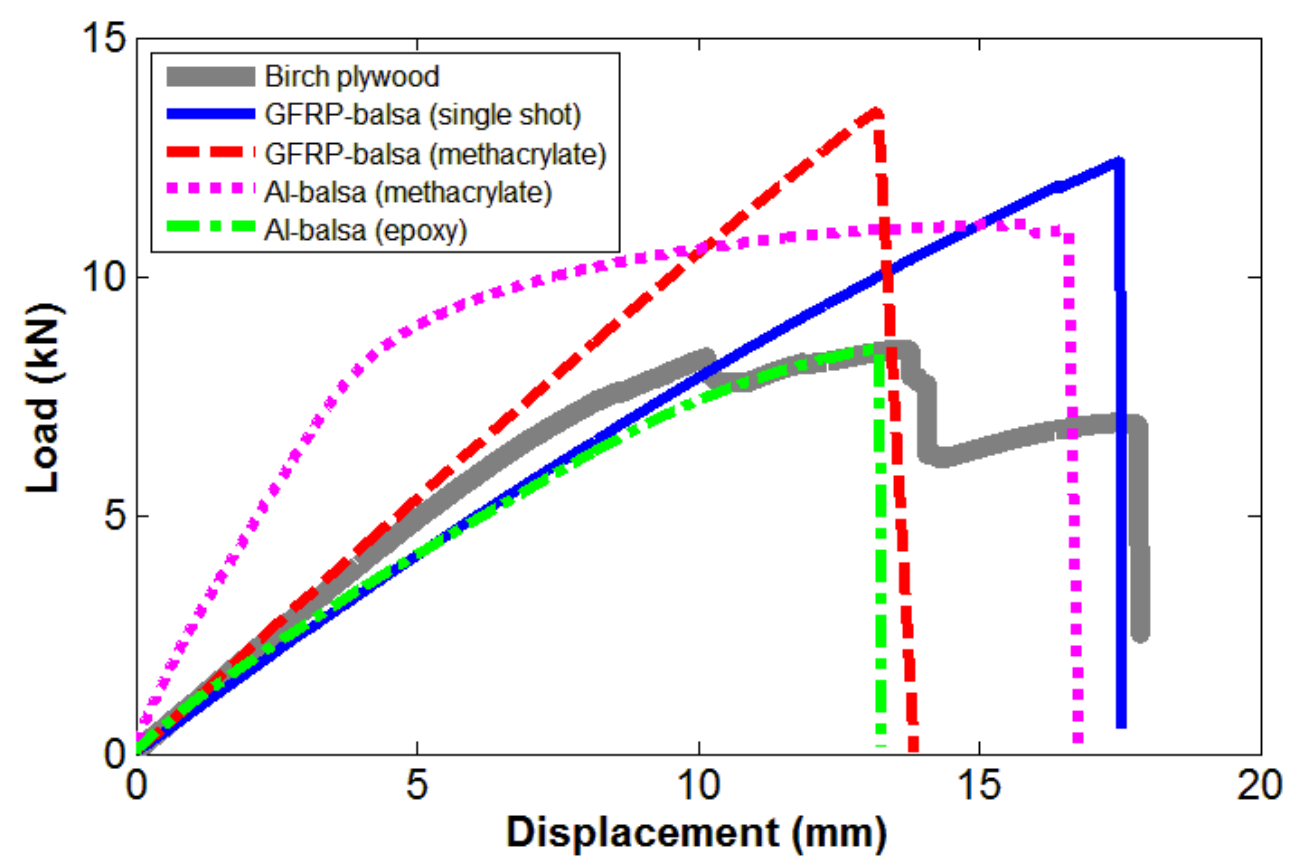

Figure 13. Typical load-displacement curves of the sandwich panels with SB.150 end-grain balsa cores in three point bending, compared to birch plywood. 

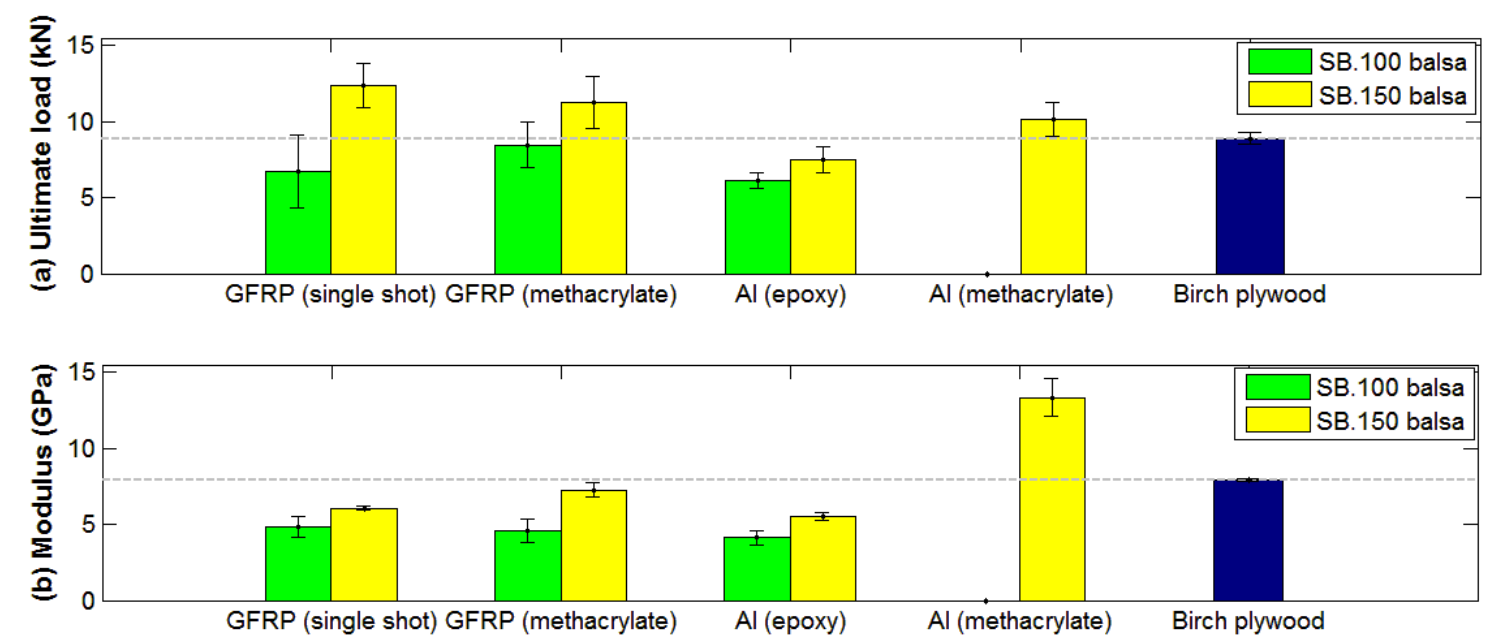

Figure 14. (a) Mean ultimate load and (b) mean flexural modulus of the sandwich panels in three point bending, compared to birch plywood. Error bars indicate standard deviation.

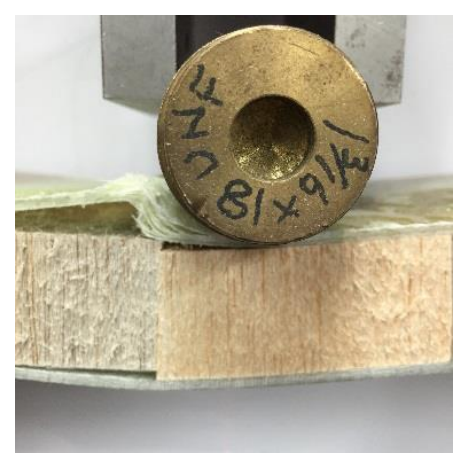

(a)

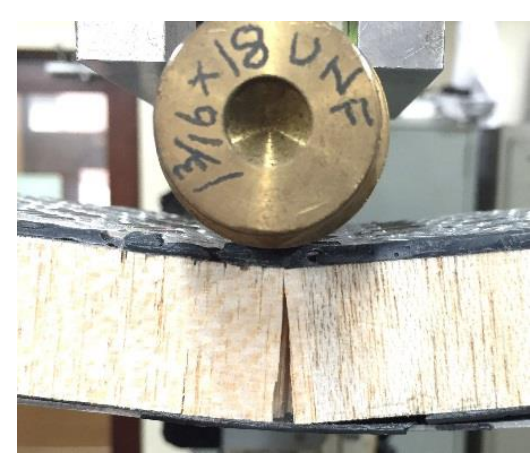

(b)

Figure 15. (a) Core shear failure observed in GFRP-balsa (SB.150) sandwich panels. (b) Face sheet yielding, followed by core shear failure observed in methacrylate bonded aluminium-balsa (SB.150) sandwich panels.

The load-displacement curves obtained from large panel testing of demonstrator sandwich panels and birch plywood of the same dimensions are shown in Figure 16. It is evident that the GFRP-balsa (SB.150) panel once again had superior strength and comparable stiffness in comparison to birch plywood. This result is encouraging since this application is more strength than stiffness limited. It is also apparent from Figure 16 that the GFRP-balsa (SB.150) sandwich panel can withstand approximately four times the forklift wheel load of $12.25 \mathrm{kN}$ that is commonly seen in-service. This panel ultimately failed at the top face sheet (Figure 17), which is in compression, at a load of approximately in $45 \mathrm{kN}$. In contrast to this, the methacrylate bonded aluminium-balsa (SB.150) sandwich panel failed prematurely at approximately $12 \mathrm{kN}$ as a result of face sheet debonding. 


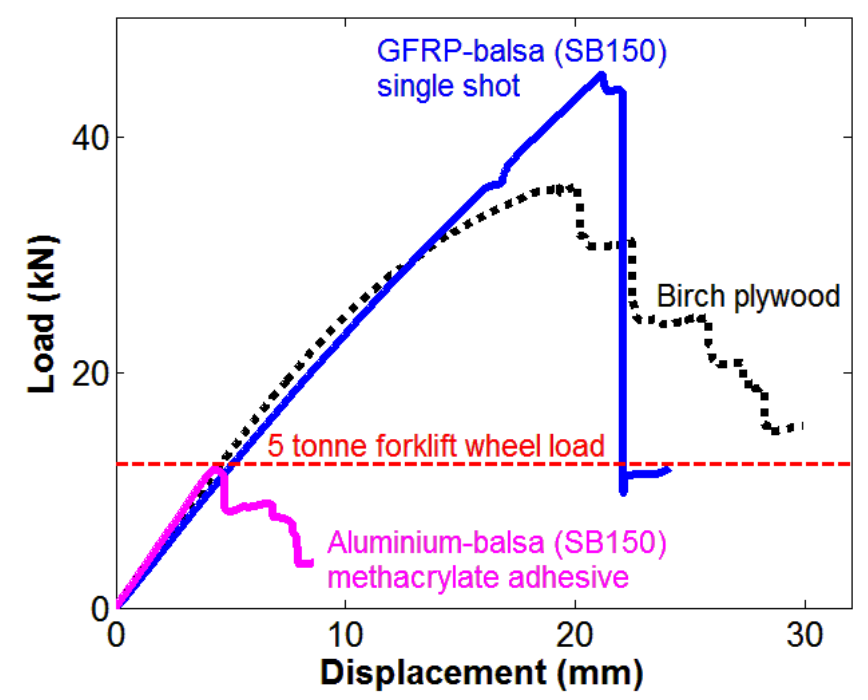

Figure 16. Load-displacement curves obtained from large panel $(500 \times 400 \times 30 \mathrm{~mm})$ testing with loading through a simulated forklift wheel (contact area $180 \times 80 \mathrm{~mm}$ ). The 5 tonne forklift wheel load is equivalent to $12.25 \mathrm{kN}$ applied through a single wheel in a four wheel forklift.

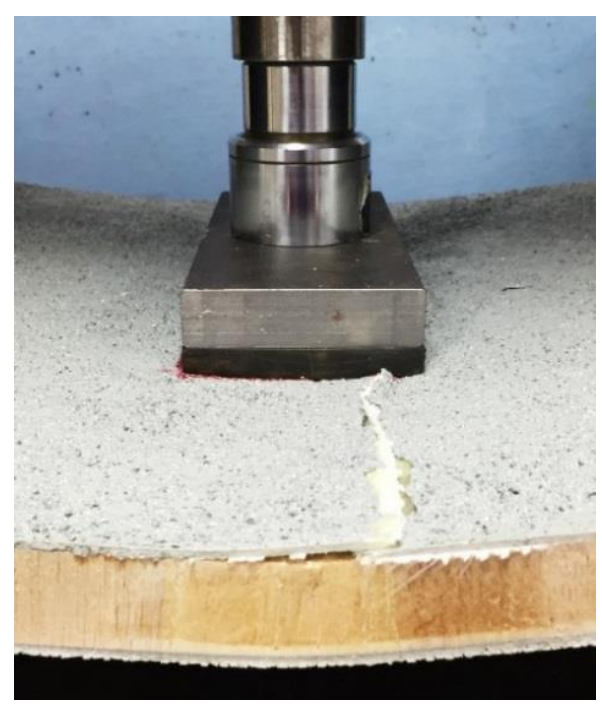

Figure 17. Top face sheet failure observed during large panel testing of $30 \mathrm{~mm}$ thick woven GFRPbalsa (SB.150) (single shot) sandwich panel with non-slip coating. Failure propagates along one edge of the rubber pad that simulates a forklift wheel.

The premature core shear failures in the intermediate density balsa (SB.100) sandwich panel specimens can be attributed to the presence of lower density constituent pieces of end-grain balsa that are found within a single sheet of rigid core (Figure 18). It is well known that the mechanical properties of balsa vary with density [12-14]. This was confirmed by determining the shear properties of the end-grain core using a novel 'hole-punch' test, described in 
Appendix C. Results of the shear testing (Figure 19) show the significantly reduced shear strength and stiffness of the lower density constituent blocks present within a single sheet of core material. This is most likely to be the cause of the adverse flexural properties observed in many of the SB.100 sandwich panel specimens. This problem was overcome by using the higher density SB.150 end-grain balsa core, which has been shown to have superior shear properties here and by Osei-Antwi et al. [14].

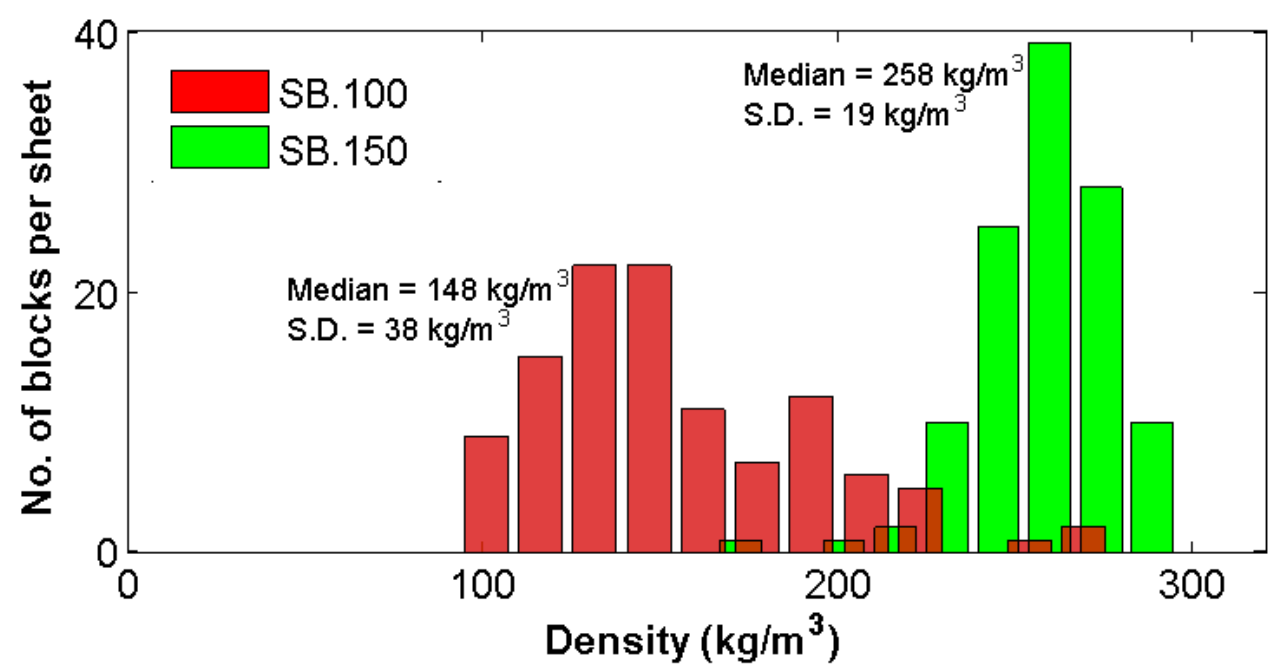

Figure 18. Histogram of the density of constituent blocks within single sheets of rigid Baltek SB.100 and SB.150 end-grain balsa core. Medians and standard deviations (S.D.) are also shown.

(a)

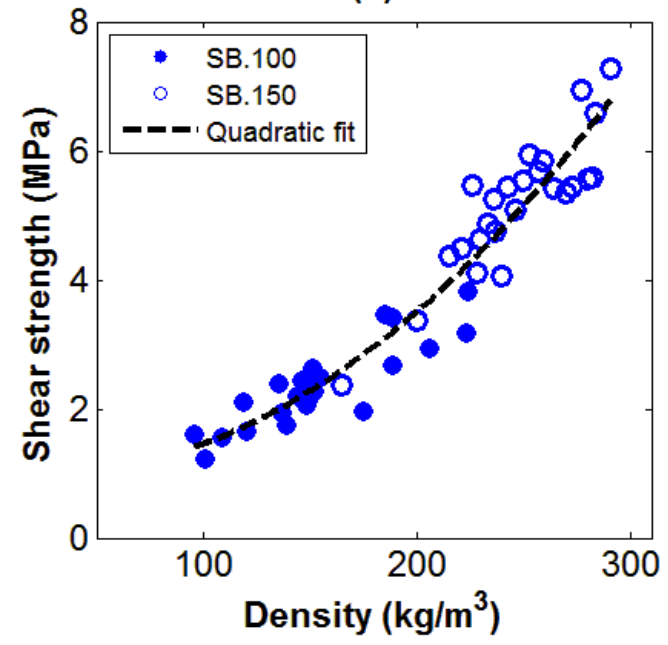

(b)

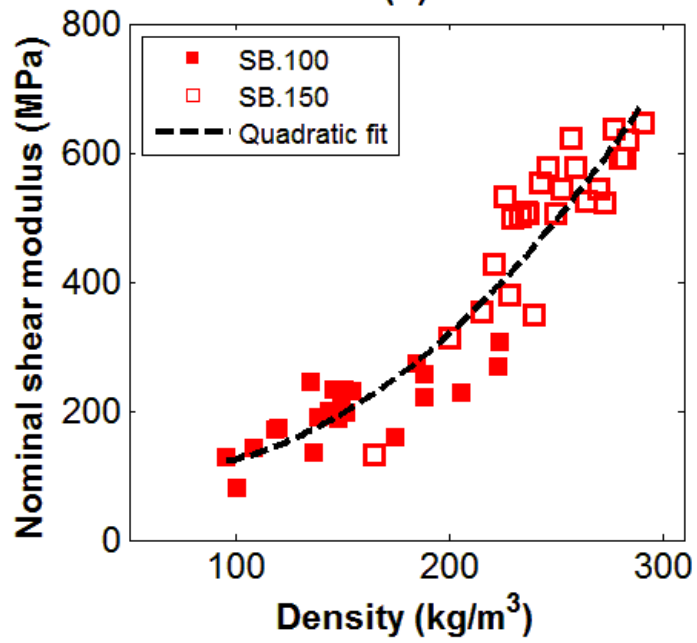

Figure 19. Variations in (a) Shear strength and (b) nominal shear modulus, with density of end-grain balsa core used in sandwich panel construction. Properties determined through 'hole-punch' test (described in Appendix C). 
While cost and mechanical performance are the two main concerns that sandwich panel decking needs to satisfy to be used successfully in this application, there are other practical issues that need to be considered. For example, safety dictates that it is desirable to have the exposed surface of the GFRP sandwich panel deck covered or treated with a non-slip coating. An abrasion resistant polyamine epoxy coating, commonly spray-applied to bridge decks and helidecks, should work well in this application and was successfully applied to the demonstrator panel (Figure 17).

Since road freight trailers are generally returned to trailer manufacturers for recycling at the end of their service life, the recyclability of the sandwich panel constituent materials also needs to be taken into consideration. This issue of sustainability supports the choice of balsa as a core material over a polymer foam material. While aluminium face sheets are generally more recyclable than GFRP face sheets, the recyclability of fibre reinforced plastics is a focus of much on-going research and is expected to improve within the coming years.

Another important consideration in the application of sandwich panel decking to road freight trailers is the method of joining. Mechanical fastening is the most common form of joining hardwood decking to the trailer beams, though structural adhesives have been successfully used in the past and these can also help to reduce weight [15]. Structural adhesives are the most attractive way to bond a lightweight composite deck to steel trailer beams, though there are some issues that need to be addressed, including: surface preparation of chassis beams, curing time and curing temperature. Nevertheless, these issues have been successfully overcome in other comparable industries (e.g. bridge construction). In addition to these issues, the operating temperature of certain adhesives could be another limiting factor. For example, epoxy adhesives generally have a glass transition temperature of around $50^{\circ} \mathrm{C}$, beyond which their adhesive strength is significantly lower. Hence, adhesively bonded trailer decking could be unsuitable for use in extremely hot environments where prolonged sun exposure is likely. Finally, it is worth noting that fatigue and impact performance of trailer decking will also require some attention, but this is outside the scope of the current work.

\section{Conclusions}

Applying sandwich panels to road freight trailer decking in replacement of conventional hardwood decking has the potential to significantly reduce empty trailer weight, without compromising the structural design of the trailer chassis. The weight saving potential of sandwich panels in this application does not justify a large increase in material cost. Hence cost, as well as flexural properties, drive material selection in sandwich design. Sandwich panels with woven GFRP face sheets, and a higher density end-grain balsa core satisfy this 
material selection criterion the most effectively. The chosen sandwich panels presented here are approximately $30 \%$ lighter than conventional birch plywood trailer decking, which corresponds to a weight saving of approximately $165 \mathrm{~kg}$ in a standard $13.6 \mathrm{~m}$ long European flatbed trailer.

Premature core shear failure during three point bend testing is likely to occur in the sandwich panels, should the end-grain balsa core not be sufficiently dense. Hence, in this application it is recommended to use the highest grade (densest) end-grain core available, though there is a slight weight penalty associated with the selection of the densest core. Some practical issues (e.g. the method of joining panels to steel chassis beams) will need to be overcome before sandwich panels can be effectively used in this application. However, the majority of these issues have been successfully resolved in other industries, meaning there should be no significant technical barriers to overcome in applying sandwich panels to road freight trailers. Material and fabrication costs are the main obstacles to the practical uptake of these structures in road freight trailers.

\section{Acknowledgements}

The authors would like to acknowledge the financial support from the members of the Centre for Sustainable Road Freight and from the Engineering and Physical Sciences Research Council (Grant Reference EP/K00915X/1). The authors are also grateful to the help and guidance in sandwich panel fabrication provided by Paul Johns and Nick Warrior at the University of Nottingham, as well as for the use of the manufacturing facilities at the University of Nottingham. Finally, the assistance of Alan Heaver and Carlos Pascal at the University of Cambridge in mechanical testing is gratefully acknowledged.

\section{References}

1. Galos J, Sutcliffe M, Cebon D, Piecyk M, Greening P. Reducing the energy consumption of heavy goods vehicles through the application of lightweight trailers: Fleet case studies. Transp Res Part D Transp Environ. Elsevier Ltd; 2015; 41:40-9.

2. ISO 1496-1: Series 1 freight containers - specification and testing - part 1, general cargo containers. Washington DC: International Organization for Standardization, 1990.

3. Zenkert D. An introduction to sandwich construction. 1st ed. London: Emas Publishing, 1997. 
4. JEC Group. Composite flooring makes for versatile trailers, http://www.jeccomposites.com/news/composites-news/composite-flooring-makesversatile-trailers (2011, accessed 28 September 2015).

5. Shoukry SN, William GW, Prucz JC, Evans TH. Application of composite sandwich panels in heavy vehicle systems. Proceeedings of 18th International Conference on Composites or Nano Engineering. Anchorage, Alaska; 2010. p. 363-4.

6. Steeves C, Fleck N. Material selection in sandwich beam construction. Scr Mater. 2004 May; 50(10):1335-9.

7. Granta Design Limited. CES EduPack 2013 Software. Cambridge, UK, 2013.

8. Ashby M. Material selection in mechanical design. 3rd ed. Oxford: Elsevier; 2005.

9. Vaiday U. Composites for automotive, truck and mass transit: materials, design, manufacturing. Lancaster, US: DEStech Publications, 2011.

10. 3AComposites Core Materials. Baltek SB Data Sheet, http://www.airexbaltekbanova.com/baltek-sb-balsa.html (2014, accessed 31 July 2014).

11. Ashby M, Evans T, Fleck NA, Hutchinson JW, Wadley HNG, Gibson LJ. Metal foams: a design guide. 1st ed. Burlington: Elsevier Science, 2000.

12. Easterling KE, Harrysson R, Gibson LJ, Ashby MF. On the mechanics of balsa and other woods. Proc R Soc A Math Phys Eng Sci. 1982; 383(1784):31-41.

13. Borrega M, Gibson LJ. Mechanics of balsa (Ochroma pyramidale) wood. Mech Mater. Elsevier Ltd; 2015; 84:75-90.

14. Osei-Antwi M, De Castro J, Vassilopoulos AP, Keller T. Shear mechanical characterization of balsa wood as core material of composite sandwich panels. Constr Build Mater. 2013; 41:231-8.

15. Noonan B. Assembly Magazine. Adhesives for trailer assembly p. 38-41, http://www.assemblymag.com/articles/86655-adhesives-for-trailer-assembly (2009, accessed 31 July 2014).

\section{Appendices}

\section{Appendix A. Flexural rigidity and failure collapse loads}

\section{Nomenclature}

$b=$ panel width,

$c=$ core thickness,

$D=$ Flexural rigidity,

$E=$ Young's modulus,

$M=$ panel mass,

$M_{1}=$ stiffness selection index,
Subscripts

$b=$ material property in bending,

$c=$ core material property,

$f=$ face sheet material property,

$C S=$ core shear,

$F Y=$ face yield,

$I D=$ ductile indentation, 


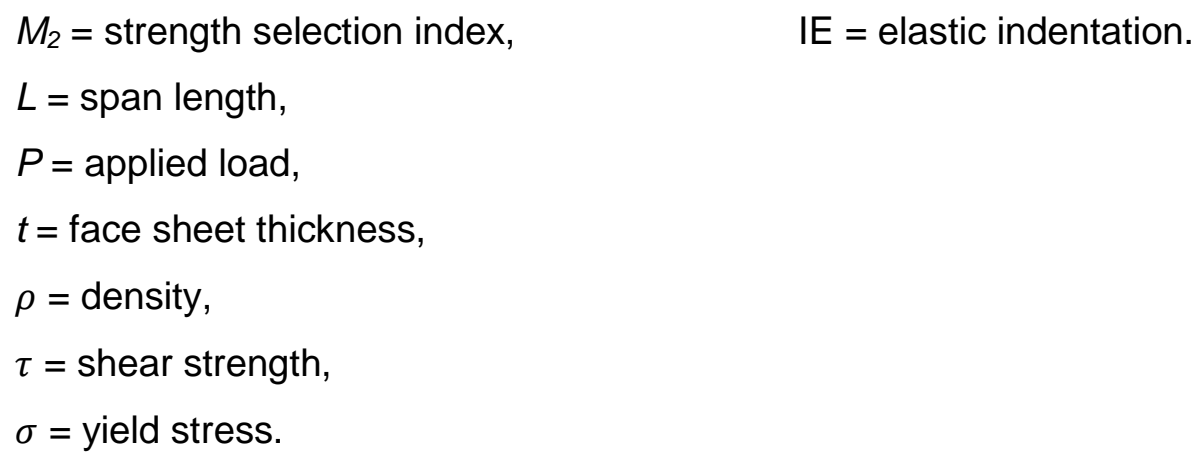

Flexural rigidity of each sandwich panel, calculated as per [11]:

$$
D=\frac{E_{f} b t(t+c)^{2}}{2}+\frac{E_{f} b t^{3}}{6}+\frac{E_{c} b c^{3}}{12}
$$

Core shear failure occurs when the shear strength of the core is exceeded.

$$
P_{C S}=2 b(t+c) \tau_{c}
$$

Face yielding occurs when the axial stress in the face sheet reaches the yield strength of the material.

$$
P_{F Y}=\frac{4 b t(t+c) \sigma_{f}}{L}
$$

Ductile indentation occurs when the face sheets are assumed to form plastic hinges at the boundaries of the indentation region.

$$
P_{I D}=2 b t\left(\sigma_{c} \sigma_{f}\right)^{1 / 2}
$$

Elastic indentation occurs when the face sheets remain elastic while the core yields plastically. In this case, the face sheets behave as a beam column upon a non-linear foundation, which is the core.

$$
P_{I E}=b t\left(\frac{\pi^{2}(t+c) E_{f} \sigma_{f}^{2}}{3 L}\right)^{1 / 3}
$$




\section{Appendix B. Failure mode map methodology}

In order to construct sandwich failure mode maps, it is first necessary to define the following non-dimensional material and geometric parameters:

$$
\bar{t}=\frac{t}{c} ; \bar{c}=\frac{c}{L} ; \bar{\sigma}=\frac{\sigma_{c}}{\sigma_{f}} ; \bar{\tau}=\frac{\tau_{c}}{\sigma_{f}} ; \bar{E}=\frac{E_{c}}{\sigma_{f}} ; \text { and } \bar{\rho}=\frac{\rho_{c}}{\rho_{f}}
$$

A non-dimensional load index $\hat{P}$ is defined as

$$
\hat{P}=\frac{P}{b L \sigma_{f}}
$$

The mass of the sandwich beam $M$ is calculated as

$$
M=b L\left(2 t \rho_{f}+c \rho_{c}\right)
$$

and the non-dimensional mass index $\widehat{M}$ is defined by substituting the non-dimensional parameters from Equation 8 into Equations 9 and 10.

$$
\widehat{M}=\frac{M}{b L^{2} \rho_{f}}=\bar{c}(2 \bar{t}+\bar{\rho})
$$

The failure loads of the competing collapse modes (Equations 4 to 7) can also be nondimensionalised in a similar fashion, as shown in Equations 12 to 15.

$$
\begin{gathered}
\hat{P}_{C S}=2 \bar{\tau}(\bar{t}+1) \bar{c} \\
\hat{P}_{M}=4 \bar{t}(\bar{t}+1) \bar{c}^{2} \\
\hat{P}_{I D}=2 \bar{t} \bar{c} \bar{\sigma}^{1 / 2}
\end{gathered}
$$




$$
\hat{P}_{I E}=\left(\frac{\pi^{2} \bar{\sigma}^{2} \bar{E}}{3}\right)^{\frac{1}{3}} \bar{t}(\bar{t}+1)^{1 / 3} \bar{c}^{4 / 3}
$$

Having defined the non-dimensional load indices, failure mode maps can be constructed by first determining the weakest and therefore active failure mode which then gives the dominant failure regimes. The failure mode maps can also be used to optimise the sandwich panel design. The optimisation strategy outlined by Steeves and Fleck [6], finds values of $\bar{t}$ and $\bar{c}$ that minimise the mass index $\widehat{M}$ for a given load index $\widehat{P}$. The trajectory of the minimum mass design then typically lies along the failure mode boundaries, although it can also lie with the elastic indentation domain and the face yield domain. Within the elastic indentation domain, the optimal value of $\bar{t}$ is given by Equation 16 .

$$
\bar{t}=\frac{3 \bar{\rho}}{2(1-2 \bar{\rho})}
$$

Within the face yield domain, the optimal value of $\bar{t}$ is given by Equation 17 .

$$
\bar{t}=\frac{\bar{\rho}}{2(1-\bar{\rho})}
$$

\section{Appendix C. Balsa shear testing}

In order to determine the shear properties of the end-grain balsa used in sandwich panel construction, a novel 'hole-punch' style of test was used, a schematic of which is shown in Figure 20. Here the shear strength $\tau$ is calculated by $\tau=P / A$, where $A$ is the specimen thickness multiplied by the circumference of the cylindrical punch. Since the cylindrical punch pushes an almost perfectly circular piece of balsa out of the test specimen, this is considered to be a reasonable way of determining the shear strength of balsa. The test method also allows for a comparative study of balsa shear modulus. A nominal shear modulus is determined from the initial slope in the load-displacement curve produced during the testing. However, since the elastic shear strain zone is not well defined here, the resultant value of shear modulus is taken to be nominal, rather than absolute. The nominal shear modulus $G_{\text {nominal }}$ is found with the initial slope $m$ in the load displacement curve, the whole punch diameter $d$ and $A$ (Equation 18).

$$
\mathrm{G}_{\text {nominal }}=\frac{m d}{A}
$$




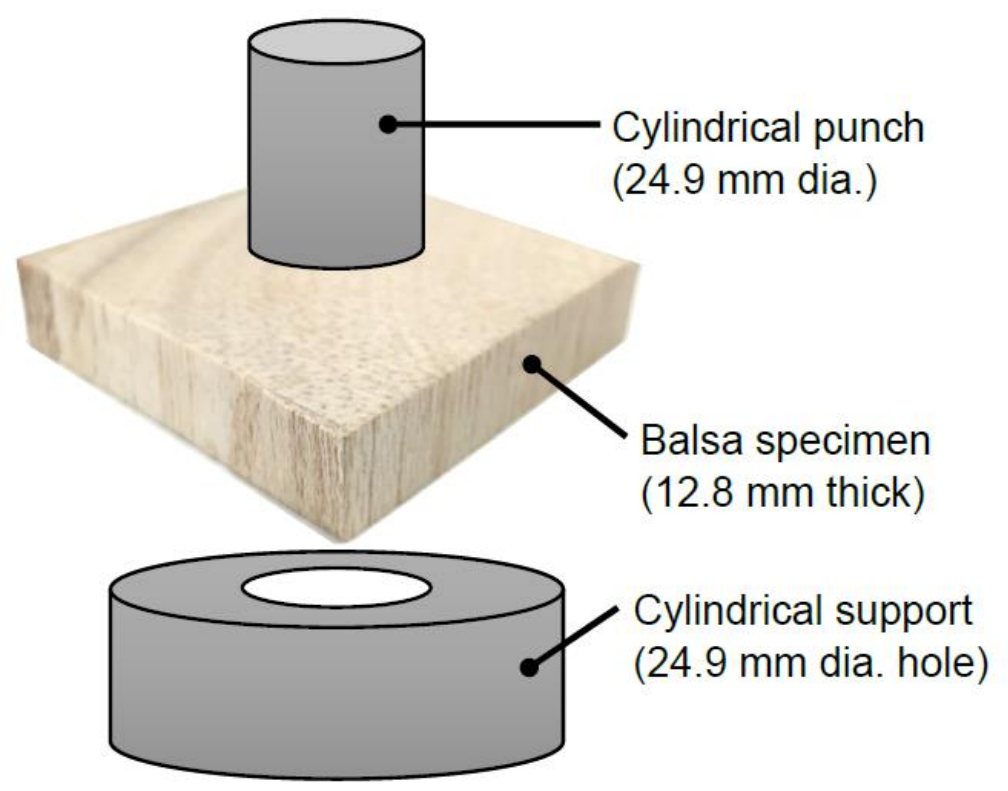

Figure 20. Schematic of 'hole-punch' test used to determine the apparent properties of constituent end-grain balsa blocks.

\section{Appendix D. Supplementary material}

Supplementary data associated with this article can be found online at: (DOI TBD) 